\title{
Research on Applied Undergraduate Education Based on Flipping Classroom 2.0
}

\author{
Chi Zhang ${ }^{1}$ Yanling Zhou ${ }^{1}$
}

\author{
School of Artificial Intelligence and Big Data, Hefei University, Hefei, Anhui 230601, China \\ *Corresponding author. Email: zhouyanl@hfuu.edu.cn
}

\begin{abstract}
With the advent of the information age in a setting of Industry 4.0, the demand for talent in society has also begun to change. How to cultivate innovative talents who can meet the needs of the society is a hot topic in the education research of applied undergraduate colleges. This paper summed up the connotation of flipping classroom 2.0, analysed the problems existing in applied undergraduate education, and expounded the advantages of flipping classroom 2.0 application to applied undergraduate colleges. Finally, a new teaching model based on flipping classroom 2.0 is constructed, the value of the teaching model is also discussed.
\end{abstract}

Keywords: Applied Undergraduate, Flipping Classroom 2.0, Creative Drive, Innovation, Entrepreneurship.

\section{INTRODUCTION}

The flipping classroom (The Inverted Classroom [1] and The Classroom Flip [2]) originated from front-line teachers' teaching, which is a teaching model that combines the actual teaching situation and reverses the teaching process inside and outside class. In 2011, it was rated as "a major technological change affecting classroom teaching" by The Globe and Mail of Canada, and Bill Gates said that "the flipping classroom foresees the future of education". At present, the research on the theory and practice of flipping classroom has become the focus of the global education community [3-4].

Now, we have entered the Industry 4.0 era characterized by networking, big data and cloud computing. It is required to implement the national strategy of "Made in China 2025" to accelerate the construction of a strong talent country. It is necessary to cultivate new talents with innovative thinking and innovative ability, and effectively complete innovations in manufacturing technology, products, models, formats and organizations to accelerate the transformation from a big manufacturing country to a strong manufacturing country, and implement the transformation upgrading and management innovation of manufacturing industry under the background of informationization [5]. It was also pointed clearly in the "Thirteenth Five-Year Plan" (2016-2020) that talents are the first resource to support the development. It is required to accelerate the development of talent development system and policy innovation, establish an internationally competitive talent system advantage, improve the quality of talents and optimize the talent structure [6].

Applied undergraduate education is an engineering education that aims to cultivate talents with solid theoretical foundation and strong ability to analyze and solve problems. The educational objectives reflect the unity of occupation, professionalism and foundation [67]. Especially under the background of "mass entrepreneurship and mass innovation", Made in China 2025 and Industry 4.0, the engineering teaching model of applied undergraduate colleges should be further changed and the teaching objectives should be improved to meet the needs of STEM engineering education and "maker education". Therefore, the research on the popular flipping classroom in the education of applied undergraduate colleges should also be upgraded from the traditional flipping classroom 1.0 to the creationoriented flipping classroom 2.0 [8].

\section{CONNOTATION OF FLIPPING CLASSROOM 2.0}

Compared with the traditional classroom teaching, flipping classroom is a teaching model that reverses knowledge transfer and internalization. It can be basically summarized as follows: Before the class, the students learn new knowledge and new concepts by watching "micro-video" and other learning resources created by the teachers, and complete the transfer of basic conceptual knowledge. During the class, the 
teachers organize the students to carry out independent investigation, group cooperation and other learning activities according to the problems encountered by students in the learning process, and complete the internalization of knowledge. The teaching model of this form is called flipping classroom 1.0. At present, this teaching model of flipping the teaching process through "micro-video" has been widely studied and practiced by the educators at home and abroad.

Flipping classroom 2.0 refers to a new teaching paradigm with complementary practical thinking that integrates fipping classroom with maker education to cultivate creative talents [9]. This teaching paradigm is the product of the combination and convergence of two kinds of thinking between maker education and flipping classroom 1.0, which achieves the upgrading and flipping of educational objectives and derives a creation-driven targeted learning mode. As shown in Figure 1, in this learning mode, the learners pursue the realization of the ultimate goal "creation". Other abilities of knowledge, understanding, application, analysis, evaluation and synthesis are also exercised intentionally or unintentionally during the realization of "creation". Therefore, there is no need to emphasize the realization of other links [10]. This is not only the reverse innovation of educational goals, but also shows many destructive innovation features, which enables the educators to focus directly on the core issues of education: talent training.

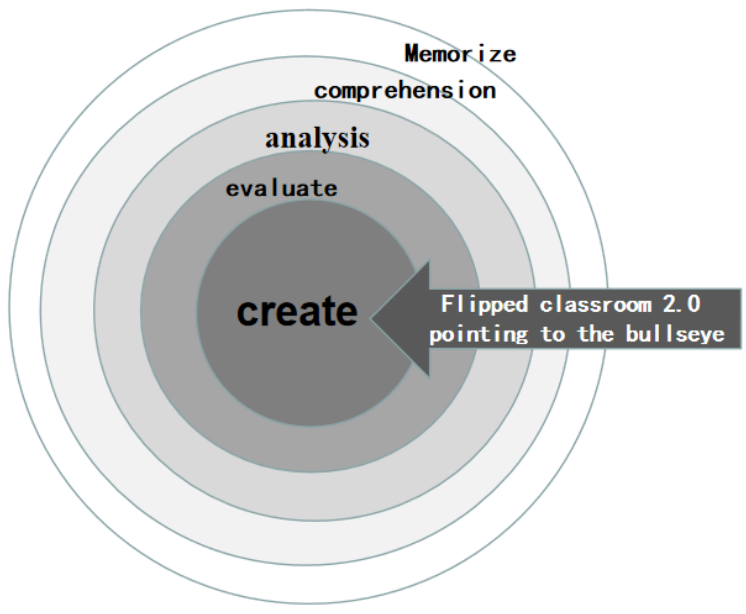

Figure 1 Creation-driven targeted learning model.

Flipping classroom 2.0 is built on the basis of creation-driven learning theory. It started directly from the "creation", and formed the complementary practical thinking combining the "bottom-up" and "top-down" in Bloom's pyramid of cognitive goals (knowledge, understanding, application, analysis, evaluation and synthesis) through bottom-up cognitive enhancement and top-down thinking innovation. As shown in Figure 2 , this combination of top-down and bottom-up teaching objectives are conducive to breaking through the "cognitive ceiling" and effectively making up the shortcomings of a single route, which not only ensures the completion of the students' knowledge skills and cognitive ability goals, but also enables the achievement of advanced cognitive goals.

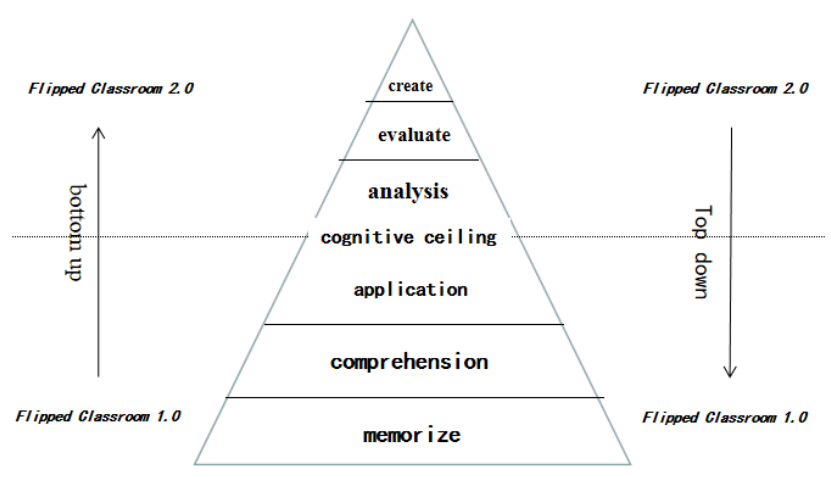

Figure 2 Innovative practice mape for flipping classroom 2.0.

\section{PROBLEMS EXISTING IN THE TEACHING AND EDUCATION OF APPLIED UNGRADUATE COLLEGES}

According to Weiner's success or failure attribution theory, the problems existing in the teaching of applied colleges can be divided into two aspects: internal factors and external factors. Internal factors refer to the problems of the colleges themselves, such as the input in education, teachers' teaching methods, and students' learning enthusiasm, etc. External factors include geographical environment and social recognition. Specifically, it can be summarized as follows: the students lack motivation for independent learning, lack of learning methods, lack of clear career planning, and incorrect learning attitude. The teachers' teaching philosophy is backward. The teaching objectives are unclear. The innovative teaching is poor and the evaluation mechanism is not perfect. The colleges themselves have problems such as insufficient investment in education, construction of campus software and hardware, and construction of campus culture.

\subsection{Insufficient Investment in Education, Unclear Orientation of Running a School and Lack of Social Recognition}

Compared with the funding sources and quantity of traditional research universities, most of the national 600 applied undergraduate colleges are local institutions. They rely mainly on financial allocations. The total funding is much smaller than that of traditional research universities, which limits the development of local applied undergraduate colleges in the introduction of teachers, teaching equipment and campus culture construction. In the process of moving from traditional 
research-based schooling thinking to application-based schooling orientation, the applied undergraduate colleges are in the stage of continuous exploration and progress. The schooling orientation of learning in the process of moving forward should be different from that of higher vocational-type applied and research-based universities, so it is easy to cause the school's schooling orientation to be unclear and take detours and wrong paths. In addition, there are some enterprises, institutions and employing units thinking that applied undergraduate colleges are the original local ordinary undergraduate institutions, which discriminate against schools and students, and lack sufficient understanding of the students and schools. As a result, the applied talents that have been cultivated lack sufficient attraction to them, resulting in the lack of social recognition of applied colleges.

\subsection{The Teachers' Teaching Methods are Backward, Lack of Practical Experience, and Lack of "Innovation" Consciousness}

Teachers, as the organizers of teaching and the executors of imparting knowledge, are the key to the success or failure of teaching activities. As the teachers of applied colleges, they should have strong learning ability, adaptability and innovation ability to meet the requirements of teachers in economic and social development. Especially for the applied undergraduate colleges, the difference between the applied higher vocational education and traditional undergraduate education is that they focus more on the cultivation of students' practical ability, innovation ability and learning ability, and emphasize more on the application of knowledge and skills. However, the college teachers basically come in to work directly after graduating from schools. This mode of going from school to school and from classroom to classroom causes the college teachers to lack practical experience and teaching skills. There is no innovation in the teaching methods. There is no creative idea in teaching form. They lack the sense of "innovation" from the contents to the means of the courses they are taught.

\subsection{Students Feel More Difficult to Learn. Their Enthusiasm for Learning is not High, and They Lack the Enthusiasm for "Creation"}

The way of knowledge learning at colleges is also different from that in secondary school. The students need to change their traditional thingking of learning and learning methods after entering the college. The knowledge learned in classroom at colleges are basic knowledge. Teachers will talk a lot in the classroom, and students need to finish homework to internalize the knowledge after the class in order to adapt to such a large amount of process of knowledge transfer and internalization. However, there are lots of courses set up in the university. The students have heavy burden in learning. The students do not have a sense of achievement in learning. Their sense of difficulty in learning is increased. Their motivation in learning is low. They lack active learning and active thinking, and their innovative thinking is slowly "worn out" in this one-way knowledge transfer and repetitive knowledge learning. In addition, the students suddenly move from being controlled by teachers to a free and open campus environment, and it is easy for them to lose their learning goals and interest in learning.

\section{THE BASIS AND ADVANTAGES OF FLIPPING CLASSROOM 2.0 IN THE EDUCATION OF APPLIED UNDERGRADUATE COLLEGES}

The value orientation of education and teaching in applied undergraduate colleges reflects the industry. The objective setting reflects the application. The curriculum setting reflects the compound property. The cultivation process reflects the practicality, and the talent evaluation reflects the pluralism. Therefore, it is different from traditional undergraduate teaching in curriculum, training mode and teaching requirements, and it should pay more attention to the "engineering", "application" and "innovation".

\subsection{Application Basis}

It can make students deeply participate in learning and form a student-centered teaching by introducing the teaching model of flipping classroom 2.0 into the applied undergraduate teaching. By introducing a specific task into teaching, it not only cultivates the students' independent learning ability and innovative ability, but also cultivates the students' ability to integrate theory with practice and apply knowledge to solve practical problems. The students not only receive knowledge transfer before the class, but also think deeply about their own problems, which stimulates the students' learning enthusiasm and enhances the students' sense of accomplishment while completing the project. This creation-driven teaching model forces the teachers to improve themselves continuously, enhance the engineering practice ability, make up for the shortage of practical teaching resources in colleges, and help the students to cultivate advanced thinking such as application, analysis and evaluation.

\subsection{Application Advantages}

There are three advantages for the teachers: First, it is easy to use. At present, there are many kinds of online education platforms and video production tools, and they all have mature technical support. It is so easy for the teachers to make high-quality videos and upload the videos. It is very convenient to upload the videos and 
other teaching resources to the online platforms by the operation in the background. Secondly, it is useful. At present, the research on the theory and practice of flipping classroom shows that the teaching model of flipping classroom has remarkable effects in improving teaching effect, stimulating the students' learning enthusiasm and improving the students' information literacy. Thirdly, the teachers want to use it. After recording videos, making learning task list and other learning resources related to the courses, their own professional quality is improved and their need for selffulfillment is satisfied, which can stimulate the teachers' learning enthusiasm and practice motivation.

For the students, they can break through the limitation of time and place, and increase the chances of students' hands-on practice. The students can complete the learning of the basic knowledge and skills according to the needs of the project before the class. The group work and group discussions as well as other learning activities can be carried out under the guidance of the teachers during the class to solve the difficult problems encountered before the class. After the class, the project gets further consolidated and improved to complete the transfer and internalization of knowledge. In this process, the students can freely control their spare time and participate deeply according to a specific learning task. The students can give full play to their subjective initiative. Each student can have the opportunity to practice and complete the project independently, and the students' creative enthusiasm can be stimulated.

For the flipping classroom 2.0 of schools, it is not just an upgraded version of flipping classroom 1.0. It has many destructive features. Therefore, the educational goal of educational reform in the applied undergraduate colleges should firstly meet the needs of society. The applied colleges should think deeply about the direction of reform, reconstruct the concept of education and teaching, redefine the functions of the schools, the roles of the teachers and the functions of the classroom, and even redesign the environment for the teachers. Flipping classroom 2.0 introduces the design concept of maker education, which is conducive to cultivating the students' innovative literacy and creative thinking. It is very important for building the campus culture with "innovative" atmosphere and cultivating the talents who meet the requirements of Industry 4.0.

\section{A NEW TEACHING MODEL FOR APPLIED UNDERGRADUATE COLLEGES BASED ON FLIPPING CLASSROOM 2.0}

The teaching model of flipping classroom 2.0 has weakened the boundary of learning activities before the class, during the class and after the class, extended the teaching activities to any time period before the class, during the class and after the class, diversified the channels for the learners to receive information, and provide more abundant types of information. The students can make full use of network tools to obtain timely and targeted learning resources, enhance the enthusiasm of the learners, and improve the teaching effect. As shown in Figure 3.

Before the class, the teacher divides the students into several learning groups, each of which is randomly composed of the students with different learning levels and abilities. In the guidance before the class, the teacher collects the knowledge materials related to the teaching contents, design the teaching cases, and focuses on the teaching cases to make learning task list. The learning task list includes: Learning guide, learning objectives, problem design, interactive learning resources, learning test, learning reflection and learning archives. Then, the produced micro-videos, courseware and other related learning resources are delivered to the students through the online teaching platforms. The students follow the requirements of the learning task list for independent learning before the class. The communication can be carried out between the teachers and students, and the students and students through the timely or non-timely tools to solve the problems encountered in self-learning and form classroom learning report materials. 


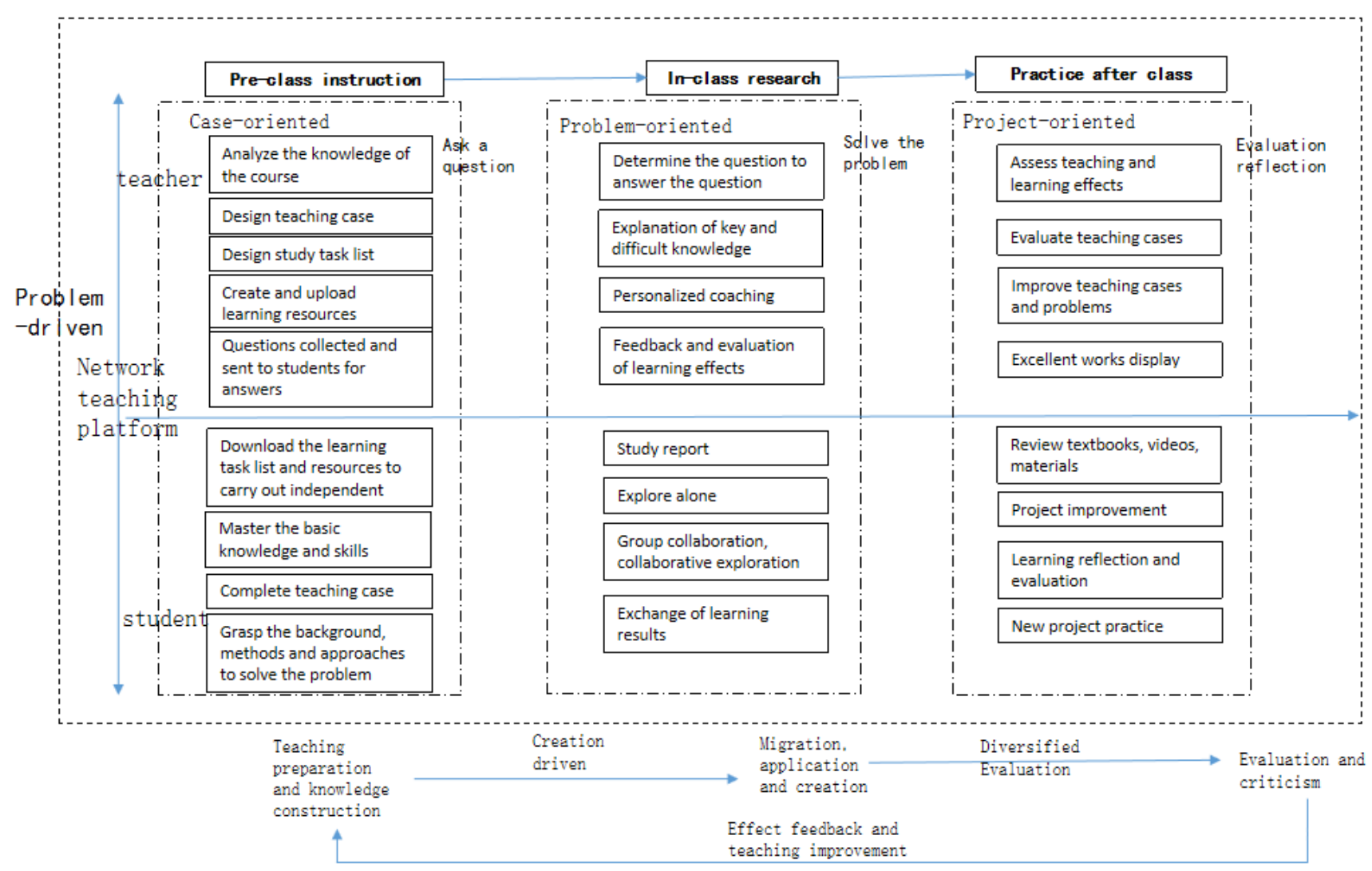

Figure 3 A new teaching model for applied undergraduate colleges based on flipping classroom 2.0.

The main objective during the class is to focus on the solution of the problems. In the teaching research during the class, the teacher should summarize the problems in the communication before the class. Guided by the problems, the students are guided to carry out independent exploration, group collaboration, cooperative exploration and other activities. Personalized counseling is provided for the students. Students' thinking can be opened and collided. It can form solutions to problems from various perspectives and realize the deep learning.

After the class, the teachers need to evaluate the applicability of the teaching cases and improve the teaching cases through the guidance before the class and the research during the class. Besides, the works of excellent students are displayed. The students check the gaps and fill in the gaps through tests, online communication, lab project practice and offline group communication. The learning projects before the class and during the class are improved by repeating the videos, studying the teaching materials and consulting the materials again. Finally, the teacher summarizes and evaluates the study and carries out new project practice, so that the students are always in an atmosphere of analyzing themselves, judging others and creating applications.

\section{CONCLUSIONS}

It needs to cultivate applied talents that meet the requirements of Industry 4.0 and Made in China 2025. The cultivation of applied talents should abandon the homogenized and standardized talent cultivation mode of traditional classrooms. It is required to integrate the education model of flipping classroom 2.0 of maker education, focus on the creative ability and practical innovation, and provide the students with more opportunities to participate in learning, which is conducive to cultivating the students' advanced thinking such as application, analysis, evaluation and creation, providing the students with better personalized counseling and new learning experience, and providing new innovative ideas in reverse order for school education and teaching reform.

\section{ACKNOWLEDGMENTS}

Fund program: Major Teaching Reform and Research Project of Higher Education Revitalization Plan of Department of Education of Anhui Province, "Research and Practice on Training Mode of Computer Applied Talents in Local Undergraduate Colleges under the Background of 'Internet + '"(2015zdjy141), Smart Classroom Teaching Practice Project of Hefei University in 2018 "Smart Classroom Pilot of Java Web Development Technology" 


\section{REFERENCES}

[1] MaureenJ Lage, GlennJ Platt, Michael Treglia.Inverting the Classroom: A Gateway to Creating an Inclusive Learning Environment [J]. The Journal of Economic Education. 2000(1).

[2] Wesley Baker.r. The"Classroom Flip": Using Web Course Management Tools to Become the Guide by the Side [DB/OL]. http://works.bepress.com/j_wesley_baker/21/,2015 $-9-21$.

[3] Wu Renying and Wang Tan. Flipping classroom: realistic challenges and coping strategies for teachers [J]. Educational Research, 2017, 38(02): 112-122.

[4] Zhang Zhibo. Flipping learning challenges traditional thinking, Guangming Daily, (2017-0725) [2018-09-04]. http://www.edu.cn/xxh/focus/li_lun_yj/201707/t20 170725_1543076.shtml

[5] Zhu Zhiting and Lei Yunhe. Flipping classroom 2.0: towards creativity-driven wisdom learning [J]. E-education Research, 2016, 37(03): 5-12. [201709-08]. DOI: 10.13811/j.cnki.eer.2016.03.001

[6] Zhang Fuquan. The essential characteristics of applied undergraduate colleges [J]. Journal of Hefei University (Natural Sciences Edition), 2010, 20(04): 53-57. [2017-09-08].

[7] Shao Bo. On the essential properties of applied undergraduate education $[\mathrm{J}]$. Vocational \& Technical Education Forum, 2014, (13): 9-13. [2017-09-08].

[8] Liu Bangqi. Flipping classroom 2.0: trend of structural change in the teaching system [N]. Jiangsu Education News, 2015-05-06 (004).

[9] Peng Hongchao, Chen Linlin, Pang Hao and Zhu Zhiting. Creativity-oriented flipping classroom teaching style: a bridge between theory and practice $[\mathrm{J}]$. China Educational Technology, 2017(07): 58-66.

[10] Ding Yonggang, Jin Mengtian, Zhang Xin and Zhang Yuqin. The design and implementation path of the flipping classroom 2.0 teaching model based on SPOC [J]. China Educational Technology, 2017(06): 95-101 